\title{
Application of some inhibitors for improving the corrosion resistance of ceramic coatings deposited on non-alloy steel by short-pulse laser treatment
}

\author{
E.V. Kharanzhevskiy, ${ }^{1 *}$ S.M. Reshetnikov, ${ }^{1,2}$ A.V. Efimov, ${ }^{1}$ \\ F.Z. Gil'mutdinov ${ }^{2}$ and M.D. Krivilev ${ }^{1,2}$ \\ ${ }^{1}$ Udmurt State University, ul. Universitetskaya, 1, 426034 Izhevsk, Russian Federation \\ ${ }^{2}$ Udmurt Federal Research Center of the Ural Branch of the Russian Academy of Sciences, \\ ul. T. Baramzinoi, 34, 426067 Izhevsk, Russian Federation \\ *E-mail: $\underline{\text { eh@udsu.ru }}$
}

\begin{abstract}
Short-pulse laser treatment was used to deposit boron carbide and nitride-based ceramic coatings on a non-alloy steel surface. The coatings thus obtained show promising properties in terms of high hardness, wear resistance, adhesion to the substrate, and low coefficient of friction. In parallel, the coatings obtained were characterized by reduced corrosion resistance in a model borate buffer solution and under conditions of recurrent water vapor condensation in a thermal humidity chamber. Preliminary treatment of samples with solutions of some inhibitors made it possible to reduce anodic currents substantially in potentiodynamic experiments. The addition of benzotriazole, mercaptobenzothiazole, and potassium dichromate proved to be effective. Electrochemical and atmospheric corrosion tests revealed that preliminary exposure of the samples to solutions of the inhibitors indicated above made it possible to reduce the corrosion rate significantly compared to the untreated samples. Potassium dichromate occurred to be most effective.
\end{abstract}

Keywords: ceramic coating, boron carbide, boron nitride, anti-corrosion properties, inhibitory treatment.

Received: November 5, 2019. Published: January 16, 2020

doi: $\underline{10.17675 / 2305-6894-2020-9-1-3}$

\section{Introduction}

Over the past few decades, the search for new materials with an improved combination of mechanical and protective properties becomes increasingly relevant because of its high technological and economic importance. The majority of components in machinery manufacturing are made of iron-containing steels and alloys. An increase in specific load on a motor or machine unit requires efficient technologies of surface modification to combine the intrinsic properties of ceramic coatings with those of metal alloys. The application of ceramic coatings to steel or preparation of metal matrix composite materials through the addition of solid ceramic particles to a steel matrix increases the hardness, wear, and heat resistance, and also reduces the coefficient of friction [1,2]. These 
properties of materials provide their extensive application in the machine industry, engine building, air transport, and nuclear power stations.

The particles of silicon carbide $(\mathrm{SiC})$, aluminum oxide $\left(\mathrm{Al}_{2} \mathrm{O}_{3}\right)$ [2], boron carbide $\left(\mathrm{B}_{4} \mathrm{C}\right)$ [3], boron carbonitride [4], chromium carbide $\left(\mathrm{Cr}_{3} \mathrm{C}_{2}, \mathrm{Cr}_{7} \mathrm{C}_{3}\right.$, and $\left.\mathrm{Cr}_{23} \mathrm{C}_{6}\right)$, tungsten carbide $\left(\mathrm{WC}, \mathrm{WC}_{0.5}\right)$, titanium boride $\left(\mathrm{TiB}_{2}\right)$ [5], and zirconium diboride $\left(\mathrm{ZrB}_{2}\right)$ [6] usually form a strengthening phase in metal matrix composites (MMC). Boron carbides and carbonitrides are promising materials for various applications [1] because of their low specific density $\left(2.51 \mathrm{~g} / \mathrm{cm}^{3}\right)$ compared to other materials, for example, diamonds $\left(3.51 \mathrm{~g} / \mathrm{cm}^{3}\right), \mathrm{SiC}\left(3.21 \mathrm{~g} / \mathrm{cm}^{3}\right)$, and $\mathrm{Al}_{2} \mathrm{O}_{3}\left(3.92 \mathrm{~g} / \mathrm{cm}^{3}\right)[1,2]$. Boron carbide has a high Young's modulus (445 hPa) and hardness $(37 \mathrm{hPa})$.

Combining the properties of ceramic coatings with those of metals and metal alloys makes it possible to improve the physicomechanical properties of a surface. Such composite materials are most appropriate for high-temperature operational conditions $[1,2]$, operation under excessive wear conditions or surface degradation, where increased thermal loads are often combined with intense mechanical friction. The physicomechanical properties of these materials, their thermal stability, resistance both to oxidation and water vapors were addressed in a series of publications (see for example [7-10], etc.). At the same time, there are virtually no works that focus on the study of corrosion resistance of coatings based on boron carbides and nitrides on steels, or MMCs with a combination of these materials under electrochemical corrosion conditions. Only scattered data on the corrosion behavior of aluminum-base alloys with added boron carbide particles are available [1], where a substantial negative impact of these particles on the corrosion resistance was reported. There are numerous reports on the beneficial effect of oxide ceramics on corrosion properties only [11]. Another negative example is demonstrated by cobalt-base alloys with added boron where boron carbide particles are formed [12]. In this context, a study on the properties of $\mathrm{B}_{4} \mathrm{C}-\mathrm{Fe}$ and $\mathrm{BN}-\mathrm{Fe}$ phases formed in the system in a wide range of electrode potentials is relevant since the effect of both carbide and boride phases on the corrosion resistance of these systems may be fundamentally different depending on the range of potentials or type of corrosive environment [13].

Due to the prospects of using the surfaces of materials with deposited boron-carbide and boron-nitride coatings as hard and wear-resistant coatings, atmospheric corrosion is of certain interest. During downtimes and work interruptions, humidity condensation on friction surfaces may occur, which creates conditions for electrochemical corrosion of the entire surface or some structural elements. Therefore, it is necessary to carry out a study on the corrosion properties of the coatings under conditions of recurrent condensation of water vapors, for example, in a thermal humidity chamber.

Thin multilayered coatings based on boron carbide or nitride are usually produced by chemical vapor deposition [9]. Boron carbide and nitride can be deposited by magnetron sputtering using appropriate targets [10]. The low adhesion stability of the resultant 
coatings is the primary constraint of these methods. Such super-hard coatings are therefore deposited on hard alloy substrates and used mostly for cutting tools.

In this work, the corrosion behavior of samples with ceramic coatings based on boron carbide and nitride deposited on steel 10 substrate were studied. A borate buffer solution (BBS) with $\mathrm{pH}=7.4$ with natural aeration was used as a model corrosion environment. The conditions of atmospheric corrosion are simulated in a thermal humidity chamber (THC). The coatings were produced through short-pulse laser treatment with high energy density.

\section{Experimental}

Solid-phase coatings with three compositions (wt.\%): $\mathrm{B}_{4} \mathrm{C} ; \mathrm{B}_{4} \mathrm{C}-40 \% \mathrm{BN} ; \mathrm{B}_{4} \mathrm{C}-40 \% \mathrm{BN}-$ $10 \% \mathrm{Li}_{2} \mathrm{O}$ were deposited onto steel 10 substrates with a size of $10 \times 10 \times 1 \mathrm{~mm}$. According to the previous studies, the last two compositions provided a high degree of hardness and excellent anti-friction surface properties measured in friction tests under conditions of dry slipping friction at elevated contact loads [14].

An experimental setup consisted of an ytterbium fibre laser with a maximum average power of $50 \mathrm{~W}$ and a wavelength of $1.065 \mu \mathrm{m}$ was used to apply the coatings. The laser treatment was performed in a chamber with a controlled atmosphere. The chamber was blown by pure argon for 2 min. The laser treatment was carried out by pulses with a duration of about $40 \mathrm{~ns}$, which is three-four orders longer than the relaxation time for the energy transmission from a valence-electron gas, which absorbs laser energy, to the crystalline lattice of metal parts [15]. Hence, the action of laser energy on a ceramic powder can be described by means of the mechanism of thermal conductivity. However, there is a need to take into account that the pulse duration is short enough, thus ensuring ultra-fast heating and a high temperature gradient in the treatment zone. The pulse frequency was set to $100 \mathrm{kHz}$, the pulse energy to $0.5 \mathrm{~mJ}$, and the momentary laser beam power to $5 \mathrm{~kW}$. The laser beam was focused to a spot with a size of $30 \mu \mathrm{m}$. Therefore, the momentary laser power density attained the value of about $7 \cdot 10^{12} \mathrm{~W} / \mathrm{m}^{2}$. The scanning rate was $600 \mathrm{~mm} / \mathrm{s}$. The modes of laser irradiation were selected using the procedure reported in [16].

A number of methods were used to examine the microstructure and the phase and chemical compositions. X-Ray studies were carried out on a DRON-3 diffractometer using Fe K $\alpha$ radiation. Data collection was carried out at each $2 \theta$ point with a step of $0.02^{\circ}$ and an acquisition time of $5 \mathrm{~s}$. The topography of the laser-irradiated surfaces was studied by scanning electron microscopy (SEM) with the use of a FEI INSPECT S50 microscope equipped with an energy-dispersive X-ray (EDX) detector.

The composition of surface layers was estimated with the use of X-ray photoelectron spectroscopy (XPS) on a SPECS spectrometer using $\mathrm{Mg} \mathrm{K} \alpha$ radiation (1253.4 eV) combined with a layer-by-layer surface etching by argon ions with an energy of $4 \mathrm{keV}$ and a current density of $30 \mu \mathrm{A} / \mathrm{cm}^{2}$ (the etching rate was about $1 \mathrm{~nm} / \mathrm{min}$ ). The CasaXPS software package was applied for experimental data processing. 
The corrosion-electrochemical behavior of the samples was examined by anodic polarization under potentiodynamic conditions following a procedure reported in [17]. Polarization measurements of the samples were carried out at a potential scan rate of $2 \mathrm{mV} / \mathrm{s}$. An Ipc-Pro L potentiostat and a YaSE- 2 cell at ambient temperature $20 \pm 2{ }^{\circ} \mathrm{C}$ were employed. A borate buffer solution with pH 7.4 (BBS 7.4) was used as the background electrolyte. This electrolyte was chosen since borate ions are almost indifferent in respect to electrode materials, i.e., they exhibit neither an ability to passivate the materials nor activate them (violate the passive state). The potentials $E(\mathrm{mV})$ of the polarized samples were measured with respect to the saturated silver chloride electrode. Current $I$ was calculated per $1 \mathrm{~cm}^{2}$ of the electrode surface and measured in $\mu \mathrm{A}$.

Atmospheric corrosion tests were carried out in a KTV-0.1-002 thermal humidity chamber (Russia) in accordance with GOST 9.054-75 under the conditions of recurrent humidity condensation on the samples. The testing process included examinations of the samples at fixed intervals from the beginning of the test in order to estimate the area of corrosion damage.

\section{Results and Discussion}

A high laser power density leads to an ultra-high heating rate of $10^{7} \mathrm{~K} / \mathrm{s}$ and forms a high gradient of temperatures of about $10^{8} \mathrm{~K} / \mathrm{m}$. At the stage of cooling, the solidification front moves with a velocity of up to $2 \mathrm{~m} / \mathrm{s}$. These data were obtained by computer simulations of the processes of heat and mass transfer following the procedure reported in [18]. The short duration of laser pulses gives rise to an effect of overheating in a local zone near the powder/substrate interface up to the temperature of $3500^{\circ} \mathrm{C}$, which far exceeds the melting point of boron-based ceramic powders (the melting point of $\mathrm{BN}$ is $2973^{\circ} \mathrm{C}$ [19]). The results of computer simulations revealed that simultaneously with the melting of the ceramic powder, a thin layer of the steel substrate with a thickness of about $20 \mu \mathrm{m}$ is also melted. Such a limited melting depth is a result of a high gradient of temperatures in the irradiated zone. Against this background, the solidification of the melt is a strongly nonequilibrium process leading to the formation of metastable phases, as it was demonstrated in [20]. The active mixing of the melt at high temperatures results in an interaction between the boron-based ceramics and the melted steel. Based on the thermodynamic estimation of oxidation-reduction reactions [21], it was shown that such reactions are thermodynamically allowed if the temperature increases significantly.

All the experiments revealed that the short-pulse laser alloying of the ceramic coatings on the steel substrate resulted in a high degree of adhesion of the coatings obtained. In addition, the method makes it possible to produce multilayered coatings without exfoliation that can emerge from significant internal compression stresses in the steel substrate and tensile stresses in the external ceramic layer. Figure 1 demonstrates the SEM surface images of samples after the monolayer laser deposition of $\mathrm{B}_{4} \mathrm{C}-\mathrm{BN}-\mathrm{Li}_{2} \mathrm{O}$, $\mathrm{B}_{4} \mathrm{C}-\mathrm{BN}$, and $\mathrm{B}_{4} \mathrm{C}$ ceramics. One can see that the chosen modes of laser treatments make 
it possible to produce a relatively uniform surface that is also smooth and dense. In this case, the $\mathrm{B}_{4} \mathrm{C}-\mathrm{BN}-\mathrm{Li}_{2} \mathrm{O}$ ceramic coating is free from cracks (see Figure 1a), as distinct from the samples with the $\mathrm{B}_{4} \mathrm{C}-\mathrm{BN}$ and $\mathrm{B}_{4} \mathrm{C}$ compositions where a network of microcracks is observed across the surface of the samples (see Figure $1 \mathrm{~b}$ and 1c). Thus, the addition of lithium oxide to the composition of ceramic coatings has a positive impact on the reduction of tensile stresses within the surface layers of the sample and smoothes away the cracks. One can see from Figure 1d that there is no cracking or exfoliating of the $\mathrm{B}_{4} \mathrm{C}-\mathrm{BN}$ coating, which is observed with the coatings of other compositions. Figure 1d also demonstrates traces of mixing of the melt and heterogeneous regions with various concentrations of iron emerging on the surface. EDX data (see Table 1) indicates that the film surface contains boron, carbon, nitrogen, oxygen (where lithium oxide was added), and iron that emerges on the surface because of remelting of a ceramic layer on the substrate and a reaction of boron carbide and nitride with iron.
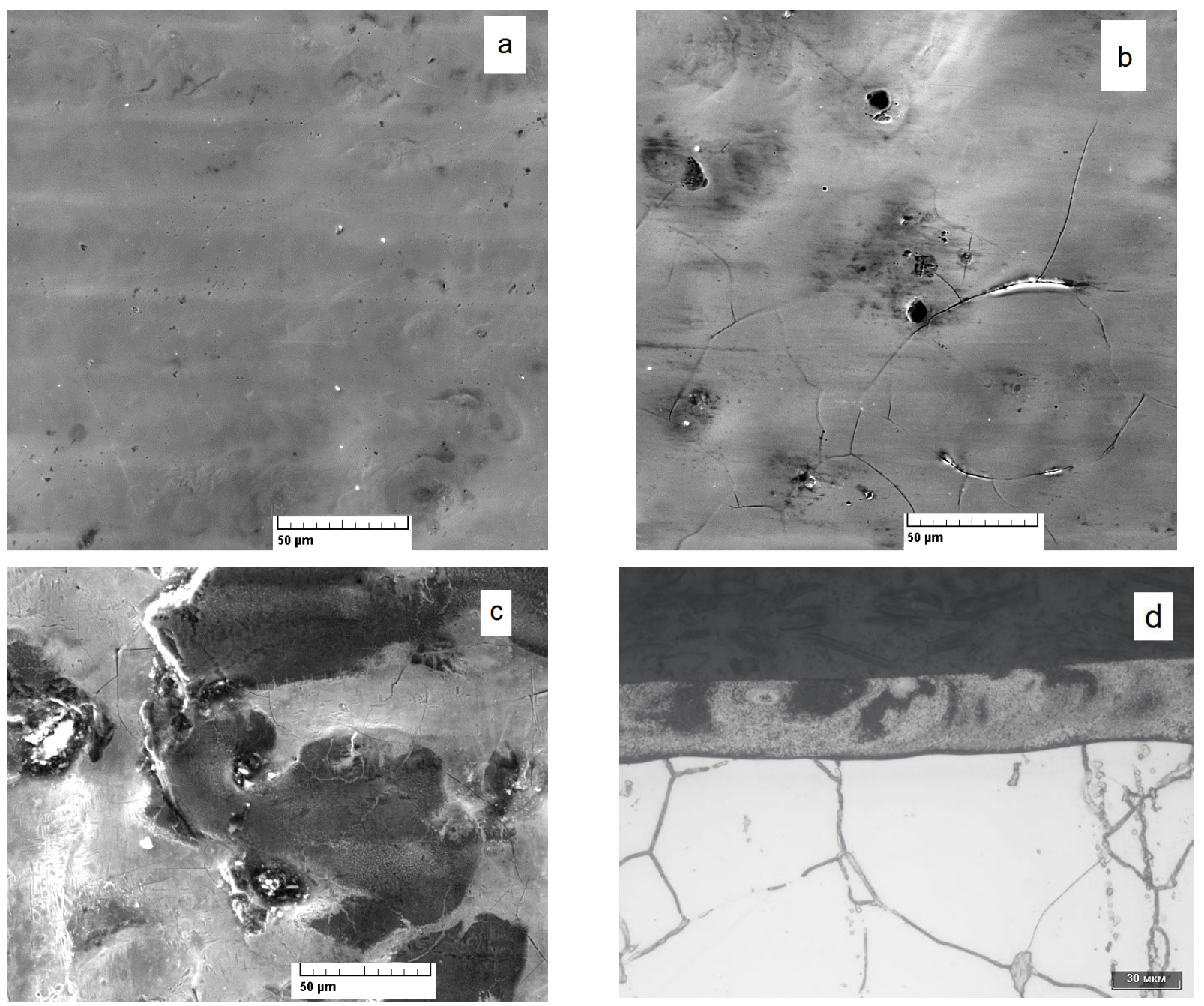

Figure 1. SEM surface images of the samples with the compositions $\mathrm{B}_{4} \mathrm{C}-\mathrm{BN}-\mathrm{Li}_{2} \mathrm{O}$ (a), $\mathrm{B}_{4} \mathrm{C}-\mathrm{BN}(\mathrm{b})$, and $\mathrm{B}_{4} \mathrm{C}(\mathrm{c})$, and a cross-section of a sample with the $\mathrm{B}_{4} \mathrm{C}-\mathrm{BN}$ coating after etching (d). 
Table 1. Elemental surface compositions of the samples based on EDX analysis, at.\%.

\begin{tabular}{cccccc}
\hline Composition of the coating & B & C & N & O & Fe \\
\hline $\mathrm{B}_{4} \mathrm{C}$ & 60 & 19 & - & - & 21 \\
$\mathrm{~B}_{4} \mathrm{C}-\mathrm{BN}$ & 21 & 5 & 2.40 & - & 71.6 \\
$\mathrm{~B}_{4} \mathrm{C}-\mathrm{BN}-\mathrm{Li}_{2} \mathrm{O}^{*}$ & 18 & 4 & 1.14 & 0.87 & 75.99 \\
\hline
\end{tabular}

* The EDX technique cannot determine the concentration of $\mathrm{Li}$; the concentrations of light elements (B, $\mathrm{C}, \mathrm{N}$ ) are estimated with significant errors.

To explain the high degree of adhesion of the ceramic layer to the steel substrate, we carried out an X-ray diffraction study of the samples after the short-pulse laser treatment. The X-ray diffraction pattern indicates the presence of $\alpha$-Fe, iron borides $\left(\mathrm{FeB}, \mathrm{Fe}_{2} \mathrm{~B}\right)$, and boron carbide $\left(\mathrm{B}_{4} \mathrm{C}\right)$. The presence of $\mathrm{FeB}$ and $\mathrm{Fe}_{2} \mathrm{~B}$ phases in the treated samples is indicative of the possibility of the following chemical reactions:

$$
\begin{aligned}
& 4 \mathrm{Fe}+\mathrm{B}_{4} \mathrm{C} \rightarrow 4 \mathrm{FeB}+\mathrm{C}, \\
& 8 \mathrm{Fe}+\mathrm{B}_{4} \mathrm{C} \rightarrow 4 \mathrm{Fe}_{2} \mathrm{~B}+\mathrm{C} .
\end{aligned}
$$

Due to the low intensity of the reflections attributed to nitrides, only traces of $\mathrm{Fe}_{4} \mathrm{~N}$ are observed in the diffraction patterns. In this case, the formation of the composite ceramics containing boron carbide and nitride is confirmed by the Vickers microhardness tests. The microhardness of the $\mathrm{B}_{4} \mathrm{C}-\mathrm{BN}$ and $\mathrm{B}_{4} \mathrm{C}-\mathrm{BN}-\mathrm{Li}_{2} \mathrm{O}$ coatings was determined to be HV 2400 and HV 2100, respectively. The coatings were characterized by a low roughness (Ra 0.4) and dry sliding friction coefficient (up to 0.02) determined by sliding against a tungsten carbide counterface under contact loads of up to $120 \mathrm{MPa}$. The reasons for the improved anti-friction properties of the coatings are discussed in [14].

As already noted, the compositions of a surface layers of the samples obtained were determined by XPS measurements. Figure 2 shows the C1s and B1s spectra for the sample with the boron carbide coating. The spectra were recorded after various etching times: the spectra from bottom to top correspond to the changes in the etching time: $0,1,2$, and 3 min (to the layer depths of $0,1,2$, and $3 \mathrm{~nm}$ ). Peaks corresponding to the $\mathrm{C}-\mathrm{H}$ bond, which is similar to that in hydrocarbons, can be seen in the spectrum of carbon recorded on the surface at depths up to $2 \mathrm{~nm}$. It is highly plausible that the surface retains traces of adsorbed hydrocarbons. However, the intensity of these peaks is relatively low. Also, the peaks associated with the $\mathrm{C}-\mathrm{B}$ and $\mathrm{C}-\mathrm{Fe}$ (substrate) bonds are clearly observed in the spectra. As follows from Figure $2 \mathrm{a}$, boron exists mostly in an oxidized state on the surface (without etching), with a peak corresponding to the $\mathrm{B}-\mathrm{O}$ bond $(192 \mathrm{eV})$. It is not unlikely that it is a result of interactions between adsorbed oxygen and boron (from boron carbide) under the influence of laser irradiation. However, at depths exceeding $2 \mathrm{~nm}$, the intensity of the peak associated with the $\mathrm{B}-\mathrm{C}$ bond $(188 \mathrm{eV})$ increases, and the peak position corresponds to the original boron carbide powder. Iron exists on the surface in an oxidized 
state. However, with increasing depth of analysis, this peak disappears (the Fe2p spectra are not provided). Based on the energy of the peak, non-oxidized iron may be expected to be involved in the $\mathrm{Fe}-\mathrm{C}$ or $\mathrm{Fe}-\mathrm{B}$ bonds.

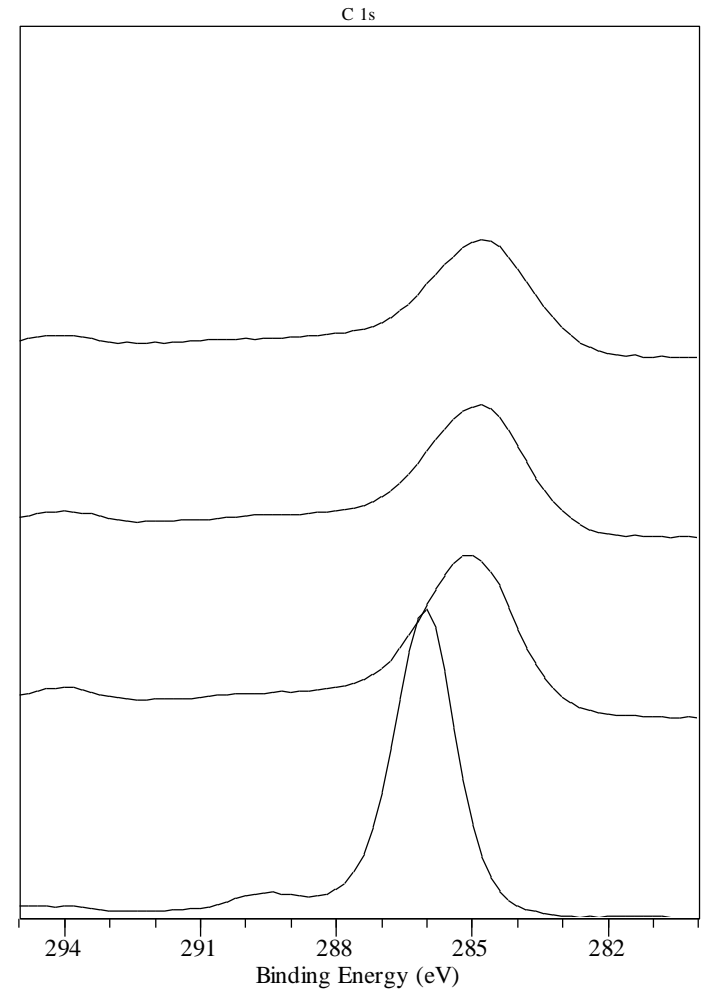

a)

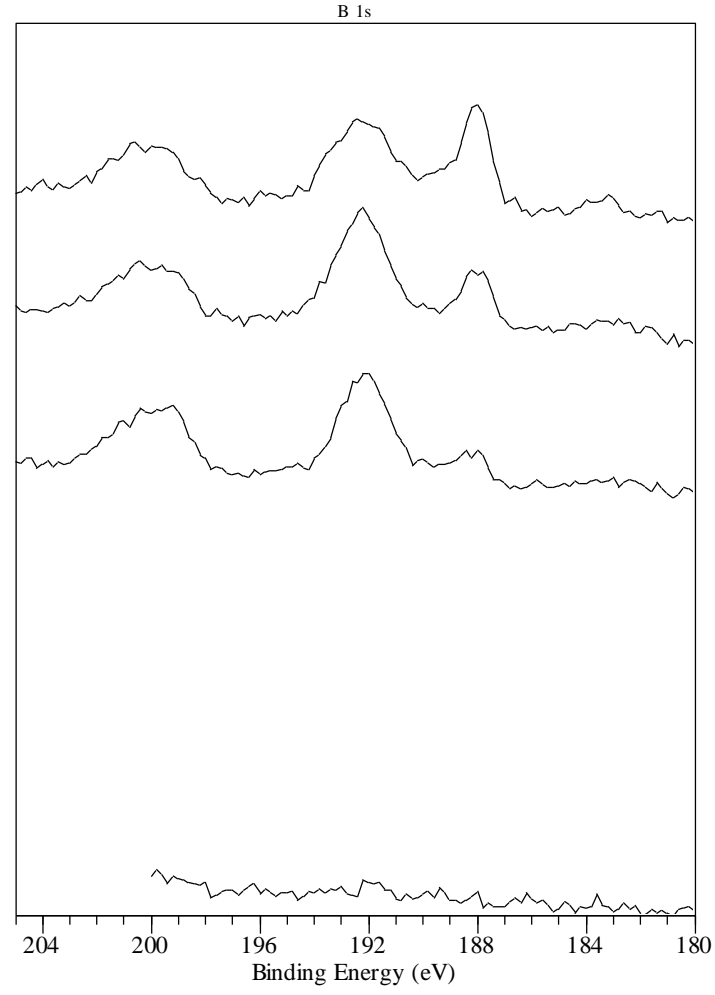

b)

Figure 2. XPS data: (a) C1s spectra; (b) B1s spectra (184-196 eV).

Summarizing the results obtained by different methods, one can conclude that the coating includes such phases as $\alpha-\mathrm{Fe}, \mathrm{FeB}, \mathrm{Fe}_{2} \mathrm{~B}, \mathrm{~B}_{4} \mathrm{C}, \mathrm{Fe}_{4} \mathrm{~N}$, and $\mathrm{Li}_{2} \mathrm{O}$, which exist in direct contact. It is known from the literature that carbides, silicides, and borides of many metals produced in compacted crystalline form by metallurgical method possess an enhanced electrocatalytic activity. As a rule, it is expressed as a high velocity (low overvoltage) of hydrogen evolution from acidic media. There are indications that metal carbides (for example, chromium carbide) can also be active in the electrochemical reduction of oxygen dissolved in neutral media [13]. Preliminary electrochemical tests of the produced ceramic coatings revealed that very high rates of anodic dissolution of the samples was observed both in acid and neutral media. An attempt to introduce a passivator (sodium nitrite) did not hinder the anodic process. The active surface dissolution of the composite coating can be attributed to the high velocity of the cathodic process on carbide and boride particles contained in the coating, by the scheme:

$$
1 / 2 \mathrm{O}_{2}+2 \mathrm{e}+\mathrm{H}_{2} \mathrm{O} \rightarrow 2 \mathrm{OH}^{-} .
$$


This cathodic process involves electrons, which results in a shift of the electrode potential of the samples towards anodic values. However, this potential shift does not bring the surface of the sample to the passive state but contributes to a further growth of anodic currents.

Various inhibitors were preliminarily tested for improving the corrosion resistance of the produced metal-matrix coatings. The effect of various inhibitors (aqueous solutions of sodium nitrite $(C=10 \mathrm{~g} / \mathrm{L})$ and potassium dichromate $(C=5 \mathrm{~g} / \mathrm{L})$, alcohol solutions of benzotriazole $(C=10 \mathrm{~g} / \mathrm{L})$ and mercaptobenzothiazole $(C=10 \mathrm{~g} / \mathrm{L}))$ was examined by the method involving preliminary formation of an inhibitor layer. The samples were immersed into a solution with one of the inhibitor concentrations mentioned above for 30-40 min and then dried in the air. Afterward, the samples were studied in the BBS using the potentiodynamic method.

The results of these studies indicated that only potassium dichromate reduced the anodic current density significantly. Figure 3 demonstrates the anodic potentiodynamic curves for the studied materials. The anodic curve of the starting untreated steel 10 is also shown for comparison. It can be seen from curve 2 that the high rate of anodic dissolution is inherent in steel with the $\mathrm{B}_{4} \mathrm{C}-\mathrm{BN}$ composite coating. A similar coating containing lithium oxide (curve 3 ) is characterized by substantially lower anodic currents, which can be attributed to the more perfect and defectless surface structure of the material containing lithium oxide (see Figure 1a). A slight decrease in the anodic current is also observed when the sample is held in a potassium dichromate solution (curve 4).

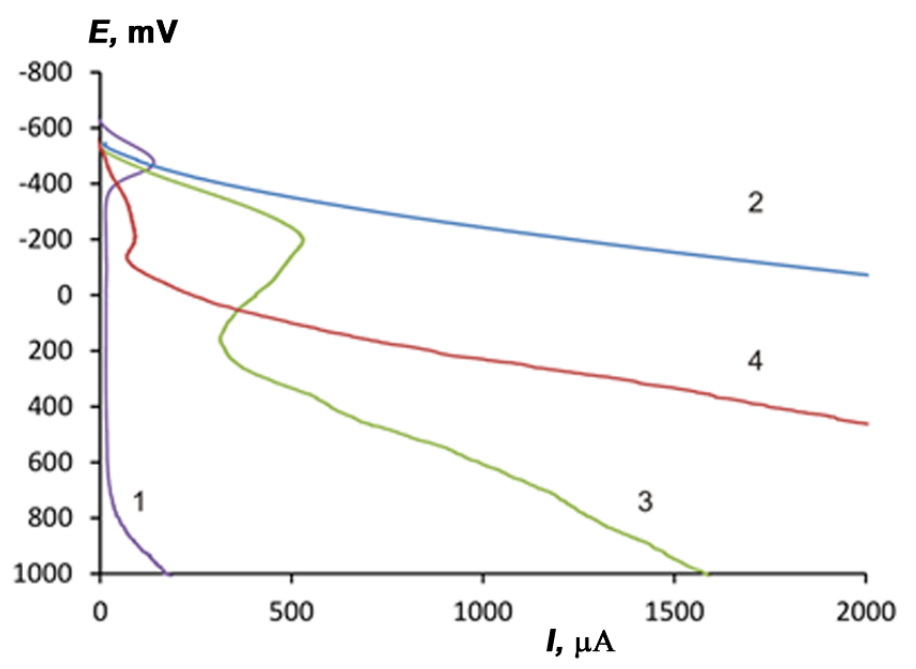

Figure 3. Potentiodynamic tests of the samples in BBS with pH 7.4: 1 - steel 10;2 - steel 10 with the $\mathrm{B} 4 \mathrm{C}-\mathrm{BN}$ composite coating; 3 - steel 10 with the $\mathrm{B}_{4} \mathrm{C}-\mathrm{BN}-\mathrm{Li}_{2} \mathrm{O}$ composite coating; 4 - steel 10 with the $\mathrm{B}_{4} \mathrm{C}-\mathrm{BN}-\mathrm{Li}_{2} \mathrm{O}$ composite coating after conditioning in the potassium dichromate solution.

As it was shown in [22], powders of carbide phases, for example, tungsten, molybdenum, and titanium carbides, as well as that of mixed carbides embedded in the 
steel $08 \mathrm{kp}$ surface contributed to the significant growth of total anodic current that did not bring the systems to the passive state even in alkaline media. It was found that under these conditions, only potassium dichromate reduced the rate of anodic dissolution of the samples significantly.

In the THC test, the samples were immersed in aqueous solutions of the inhibitors, removed from the solution after $30 \mathrm{~min}$ of exposure, and dried in the air. Afterward, the samples were placed into the THC. By visual monitoring, the moment of arising corrosion instances was detected, and the percentage of the corroded surface area was estimated (Figure 4). Table 2 summarizes the test results for the coatings exposed in a THC for 4 days. It can be seen that a noticeable improvement in the anti-corrosion properties of the coatings under study is achieved only after treatment with potassium dichromate.

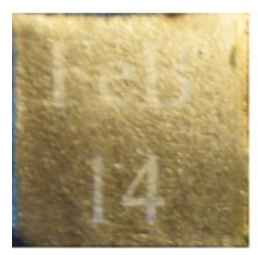

a

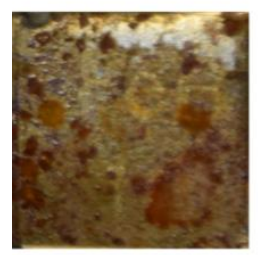

C

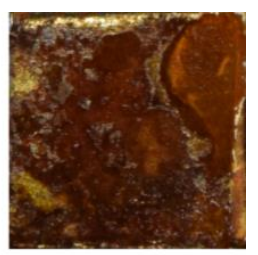

b

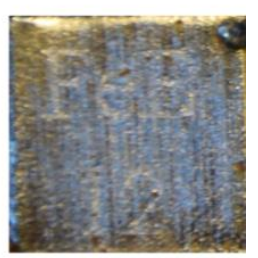

d

Figure 4. Exterior of samples with the $\mathrm{B}_{4} \mathrm{C}-\mathrm{BN}-\mathrm{Li}_{2} \mathrm{O}$ coating after atmospheric corrosion tests after THC exposure for $48 \mathrm{~h}$ : a - before the test; b, c, and d - after the test of the coatings additionally treated with inhibitors: benzotriazole (b), mercaptobenzothiazole (c), and potassium dichromate as a passivator (d).

Table 2. Effect of the coating and corrosion inhibitor (passivator) formulations on atmospheric corrosion in the tests after THC exposure. The percentage of the area damaged by corrosion after THC exposure for different periods.

\begin{tabular}{cccc}
\hline Type of coating, anti-corrosion treatment & $\mathbf{4 5} \mathbf{~ m i n}$ & $\mathbf{8 ~ h}$ & $\mathbf{4}$ days \\
\hline Untreated steel $10(0.1 \% \mathrm{C})$ & 0 & signs & 3 \\
$\mathrm{~B}_{4} \mathrm{C}$ coating, $\mathrm{NaNO}_{2}$ treatment & 0 & 50 & 100 \\
$\mathrm{~B}_{4} \mathrm{C}-\mathrm{BN}$ coating, treatment with benzotriazole & 20 & 90 & 100 \\
$\mathrm{~B}_{4} \mathrm{C}-\mathrm{BN}-\mathrm{Li}_{2} \mathrm{O}$ coating, treatment with benzotriazole & 10 & 70 & 90 \\
$\mathrm{~B}_{4} \mathrm{C}-\mathrm{BN}-\mathrm{Li}_{2} \mathrm{O}$ coating, treatment with mercaptobenzothiazole & 10 & 50 & 60 \\
$\mathrm{~B}_{4} \mathrm{C}-\mathrm{BN}-\mathrm{Li}_{2} \mathrm{O}$ coating, treatment with potassium dichromate & 0 & 0 & 1 \\
\hline
\end{tabular}




\section{Conclusions}

1. Ceramic composite coatings on non-alloyed steel 10 classified as metal-matrix composites (MMC) were obtained by short-pulse laser treatment of powdered boron carbide and nitride with addition of lithium oxide. MMC preserved the properties inherent in $\mathrm{B}_{4} \mathrm{C}$ and $\mathrm{BN}$ (hardness, wear resistance, low coefficient of sliding friction) along with firm adhesion to the substrate. XPS, XRD, and SEM data indicated that the surface of steel 10 with deposited $\mathrm{B}_{4} \mathrm{C}-\mathrm{BN}$ coating contained the phases of $\mathrm{B}_{4} \mathrm{C}, \mathrm{BN}$, iron carbides, borides, and nitrides. Peaks associated with the $\mathrm{Fe}-\mathrm{B}$ and $\mathrm{Fe}-\mathrm{C}$ bonds were found in the XPS spectra. The indicated compounds can be deemed to ensure a high degree of adhesion of the substrate to the deposited coating.

2. The studies to establish the electrochemical corrosion susceptibility of the produced samples revealed their low corrosion resistance in the background neutral borate-buffer solution. Polarization measurements showed high values of anodic dissolution currents of the samples and their lack of ability to move to a passive state.

3. Preliminary treatment of the samples with solutions of some inhibitors, which are known for their effectiveness in a neutral environment, provided a substantial reduction in the anodic currents in potentiodynamic experiments. The addition of benzotriazole, mercaptobenzothiazole, and potassium dichromate had proved to be effective. The test in THC revealed that preliminary exposure of the samples to solutions of the inhibitors indicated above made it possible to reduce the corrosion damage rate significantly compared to the untreated samples. Potassium dichromate occurred to be the most effective.

\section{Funding}

The work was supported by the Russian Science Foundation, project no. 19-79-20012.

\section{References}

1. V.A. Katkar, G. Gunasekaran, A.G. Rao and P.M. Koli, Effect of the reinforced boron carbide particulate content of AA6061 alloy on formation of the passive film in seawater, Corros. Sci., 2011, 53, 2700-2712. doi: 10.1016/j.corsci.2011.04.023

2. D.B. Miracle, Metal matrix composites - from science to technological significance, Compos. Sci. Technol., 2005, 65, 2526-2540. doi: 10.1016/j.compscitech.2005.05.027

3. J. Ye, J. He and J.M. Schoenung, Cryomilling for the fabrication of a particulate $\mathrm{B}_{4} \mathrm{C}$ reinforced Al nanocomposite, part I. Effects of process conditions on structure, Metall. Mater. Trans. A, 2006, 37, no. 10, 3099-3109. doi: 10.1007/s11661-006-0190-Z

4. V.S. Sulaeva, E.A. Maksimovsky, M.L. Kosinova and Yu.M. Rumyantsev, Analysis features of elemental composition of boron carbonitride films by EDS, Prot. Met. Phys. Chem. Surf., 2014, 50, 273-277. doi: 10.1134/S2070205114020178 
5. I.M. Poletika, T.A. Krylova, Y.F. Ivanov, M.G. Golkovskiy, V.D. Kitler, A.D. Teresov and S.A. Makarov, Fabrication of reinforcing nanostructured coatings by electron beam processing, Prot. Met. Phys. Chem. Surf., 2012, 48, 221-232. doi: 10.1134/S2070205112020153

6. V.V. Malyshev and A.I. Gab, Physicochemical properties of electrodeposits based on tungsten carbide and zirconium diboride on steels, Prot. Met., 2007, 43, 45-49. doi: $10.1134 / \mathrm{S} 0033173207010055$

7. Z. Lv, H. Fu, J. Xing, Z. Huang, S. Ma and Y. Hu, Influence of boron contents on oxidation behavior and the diffusion mechanism of $\mathrm{Fe}-\mathrm{B}$ based alloys at $1073 \mathrm{~K}$ in air, Corros. Sci., 2016, 108, 185-193. doi: 10.1016/j.corsci.2016.03.002

8. N. Baklanova, V. Lozanov and A. Titov, The first evidence of the high oxidation resistance of the novel ternary tantalum-iridium-boron phase, Corros. Sci., 2019, 160, 108178. doi: 10.1016/j.corsci.2019.108178.

9. M. Steinbruck, Oxidation of boron carbide at high temperatures, J. Nucl. Mater., 2005, 336, 185-193. doi: $10.1016 /$ j.jnucmat.2004.09.022

10. H.-S. Ahn, P.D. Cuong, K.-H. Shin and K.-S. Leeal, Tribological behavior of sputtered boron carbide coatings and the influence of processing gas, Wear, 2005, 259, 807-813. doi: 10.1016/j.wear.2005.02.096

11. I.O. Bashkova, S.M. Reshetnikov, F.Z. Gil'mutdinov and E.V. Kharanzhevskii, Laser Dispersion of Titanium and Magnesium Oxides in $\mathrm{Zr}-1 \% \mathrm{Nb}$ Alloy Affecting Surface Structure and Protective Properties, Inorg. Mater.: Appl. Res., 2019, 10, no. 1, 114-121, doi: $10.1134 /$ S2075113319010039

12. M. Hernandez-Rodriguez, D. Laverde-Cataño, D. Lozano, G. Martinez-Cazares and Y. Bedolla-Gil, Influence of Boron Addition on the Microstructure and the Corrosion Resistance of CoCrMo Alloy, Metals, 2019, 9, 307. doi: 10.3390/met9030307

13. Ya.M. Kolotyrkin and V.M. Knyazheva, Svoistva karbidnykh faz i korrozionnaya stoikost' nerzhaveyushchikh stalei (The properties of carbide phases and corrosion resistance of stainless steel), In: Korroziya $i$ zashchita ot korrozii (Corrosion and Corrosion Protection), 1974, 3, Moscow, 5-83 (in Russian).

14. A.G. Ipatov and E.V. Kharanzhevskiy, The Tribological Properties of Superhard and Functional Coatings Based on Carbide and Boron Nitride, J. Frict. Wear, 2019, 40, no. 6, 588-592.

15. J.P. Girardeau-Montaut, M. Afif， C. Girardeau-Montaut， S.D. Moustaïzis and N. Papadogiannis, Aluminium electron-phonon relaxation-time measurement from subpicosecond nonlinear single-photon photoelectric emission at $248 \mathrm{~nm}$, Appl. Phys. A, 1996, 62, 3-6. doi: 10.1007/BF01568079

16. S.N. Kostenkov, E.V. Kharanzhevskii and M.D. Krivilev, Determination of characteristics of laser radiation interaction with nanocomposite powder materials, Phys. Met. Metallogr., 2012, 113, 93-97. doi: 10.1134/S0031918X12010061 
17. S.M. Reshetnikov, E.V. Kharanzhevskii and M.D. Krivilev, Corrosion-Electrochemical Behavior of Composite Layers Produced by Laser Sintering of Nanoscale Iron-Nickel Powders, Prot. Met. Phys. Chem. Surf., 2012, 48, 729-734. doi: 10.1134/S207020511207012X

18. M.D. Krivilyov, E.V. Kharanzhevskii, V.G. Lebedev, D.A. Danilov, E.V. Danilova and P.K. Galenko, Synthesis of Composite Coatings using Rapid Laser Sintering of Metallic Powder Mixtures, Phys. Met. Metallogr., 2013, 114, 799-820. doi: $\underline{10.1134 / \mathrm{S} 0031918 X 13080073}$

19. CRC Handbook Chemistry and Physics, Ed.: D.R. Lide, CRC Press, 2008-2009, 4-53.

20. E.V. Kharanzhevskiy, Separation in liquid and the formation of supersaturated solid solutions in Fe-Cu alloys upon rapid laser melting, Phys. Met. Metallogr., 2016, 117, 889-895. doi: 10.1134/S0031918X16070097

21. M. Aizenshtein, I. Mizrahi, N. Froumin, S. Hayun, M.P. Dariel and N. Frage, Interface interaction in the $\mathrm{B}_{4} \mathrm{C} /(\mathrm{Fe}-\mathrm{B}-\mathrm{C})$ system, Mater. Sci. Eng. A, 2008, 495, 70-74. doi: 10.1016/j.msea.2007.06.100

22. E.T. Shapovalov, Characteristic anodic peaks of carbides measured on a mild steel encrusted with carbide powders, Prot. Met., 1995, 31, 593-596. 